\title{
Numerical Analysis for Remote Identification of Materials With Magnetic Characteristics
}

\author{
Yavuz Ege, Mehmet Gökhan Şensoy, Osman Kalender, and Sedat Nazlibilek
}

\begin{abstract}
There is a variety of methods used for remote sensing of objects such as acoustic, ground penetration radar detection, electromagnetic induction spectroscopy, infrared imaging, thermal neutron activation, core four-pole resonance, neutron backscattering, X-ray backscattering, and magnetic anomaly. The method that has to be used can be determined by the type of material, geographical location (underground or water), etc. Recent studies have been concentrated on the improvement of the criteria such as sensing distances, accuracy, and power consumption. In this paper, anomalies created by materials with magnetic characteristics at the perpendicular component of the Earth magnetic field have been detected by using a KMZ51 anisotropic magnetoresistive sensor with high sensitivity and low power consumption, and also, the effects of physical properties of materials on magnetic anomaly have been investigated. By analyzing the graphics obtained by 2-D motion of the sensor over the material, the most appropriate mathematical curves and formulas have been determined. Based on the physical properties of the magnetic material, the variations of the variables constituting the formulas of the curves have been analyzed. The contribution of this paper is the use of the results of these analyses for the purpose of identification of an unknown magnetic material. This is a new approach for the detection and determination of materials with magnetic characteristics by sensing the variation at the perpendicular component of the Earth magnetic field. The identification process has been explained in detail in this paper.
\end{abstract}

Index Terms-Anisotropic magnetoresistive sensor (AMR), magnetic anomaly, magnetic materials, power consumption, remote sensing.

\section{INTRODUCTION}

$\mathbf{T}$ ODAY, the remote sensing methods of materials with magnetic characteristics are widely used in applications such as geological and archeological investigations, civil engineering, health, traffic, military, etc. The type of object that is to be remotely sensed, the material from which it is made (magnetic or nonmagnetic), and the location of the object

Manuscript received March 14, 2010; revised August 12, 2010; accepted February 14, 2011. Date of publication April 7, 2011; date of current version August 10, 2011. This work was supported by the Branch of Scientific Research Projects of the Balikesir University, Turkey, under Project Code 09/14. The Associate Editor coordinating the review process for this paper was Dr. Mark Blodgett.

Y. Ege is with the Department of Physics Education, Necatibey Faculty of Education, Balikesir University, 10100 Balikesir, Turkey.

M. G. Sensoy is with the Department of Physics, Faculty of Art and Sciences, Rize Üniversity, 53100 Rize, Turkey.

O. Kalender is the Chief of Research and Development Department, KZ Mekatronik Company, 06100 Ankara, Turkey.

S. Nazlibilek is with the Nanotechnology Research Center, Bilkent University, 06800 Ankara, Turkey.

Color versions of one or more of the figures in this paper are available online at http://ieeexplore.iee.org.

Digital Object Identifier 10.1109/TIM.2011.2124651 (buried underground or water) determine the method that has to be used. Works carried out in this area are mainly focused on the detection of buried mines. In the following, major remote sensing methods and their principles are given.

1) Acoustic method: This is based on the evaluation of variation in the speed of ultrasound wave during progressing in the medium when it passes over an object [1].

2) Ground penetration radar detection: This method is based on the reflection of high-frequency electromagnetic waves from the regions with different dielectric constants and receiving the reflected waves by a receiver and recording them [2].

3) Electromagnetic induction spectroscopy: When a conductive object with a magnetic permeability is placed in a medium having an electromagnetic signal varying with time, an electric charge flow occurs in the object, and the induced current can produce a weak secondary magnetic field. Information on the object can be gathered by detecting and evaluating this secondary magnetic field [3].

4) Infrared imaging: It is a technique that is based on the detection of thermal differences occurring within the material during natural thermal variations of the environment [4].

5) Nuclear quadrupole resonance (NQR): NQR has much in common with nuclear magnetic resonance, the fundamental physical process that makes magnetic resonance imaging possible. This is a method particularly used for the detection of explosives and drugs. It is based on the detection of nitrogen isotope $\left({ }^{14} \mathrm{~N}\right)$ in the content of an explosive or a drug [5].

6) Timed neutron detection (TND): Significant reduction of time is needed to identify hidden explosives and other hazardous materials by the "neutron-in gammaout" method. It utilizes the unique neutron-moderating properties that are common to most explosives and all polymers and incorporates timing aspects to improve the measurement process. TND offers the possibility of a low-cost detector for nonmetallic land mines with small radiation exposure [6].

7) Neutron backscattering imaging: The neutron backscattering technique may be used to search for low-metallic land mines. In this technique, the neutrons are produced with a pulsed neutron generator. An image of the backscattered thermal neutron radiation is obtained with a 2-D position sensitive detector [7]. 
8) X-ray backscatter: The new X-ray Compton backscatter imaging technique, described as lateral migration radiography (LMR), was developed specifically for solution of the buried plastic land mine detection problem. The LMR imaging modality employs an array of two types of large sensitive-area detectors. Manipulation of the set of images acquired by this detector array results in systematic removal of mine-image cloaking due to soil surface features and slope [8].

9) Magnetostatic dipole field or field gradient: It is a method used in practice based on the field gradient. The inversion of the magnetostatic dipole field or field gradient is a necessary first step toward determining object location and identity [9], [10].

In this paper, remote sensing is achieved by using a magnetic anomaly method. This method can also be used for vehicle identification, traffic density observations, [11], geological studies [12], health [13], archeological investigations [14], mines, and buried explosives over the military zones [15], [16]. In recent years, the studies have been concentrated on the improvement of detection distances, accuracy, and power consumption.

In this paper, improved and manufacturing-type steels with ferromagnetic characteristics widely used in industrial applications are used. Since the magnetic permeability of this type of materials is very high, they attract the magnetic field lines of the Earth which are parallel to the ground toward themselves. In this case, there will be two components of the lines parallel to the ground: One is horizontal, and the other is vertical. If the vertical component that occurred with the availability of magnetic material can be sensed by the magnetic sensor, then it will be possible to identify the material. In order to achieve it, the sensitivity of the sensor becomes important. For this reason, in this paper, a KMZ51 un-isotropic magnetosensitive sensor with low power and high sensitivity is used. This paper is unique since reduced power consumption and highly accurate measurements can be achieved. Furthermore, this is a new approach for the identification of material with magnetic characteristics which can be achieved based on the detection of the vertical component of the Earth's magnetic field [12]-[16].

In addition, if the field lines of the Earth at a location where magnetic materials are found are constant and homogeneous, then it may give rise to some difficulties in identifying the material. This work has been carried out in an environment where the Earth magnetic field is homogeneous, and the value of it is $4.4 \times 10^{-5} \mathrm{~T}$. After installing the experiment measurement system in this environment, some materials made up of steel with various chemical compositions and magnetic permeabilities have been brought to the scanning area of the sensor. The data obtained by scanning a plane which is parallel to the plane of the materials have been analyzed and used to capture some geometric properties of the materials.

Now, we can explain the measurement system and magnetic materials, measurement results and the effect of physical characteristics of the materials on the output voltages of the sensor, mathematical variation of the sensor output signal, and identification of magnetic material based on this variation.

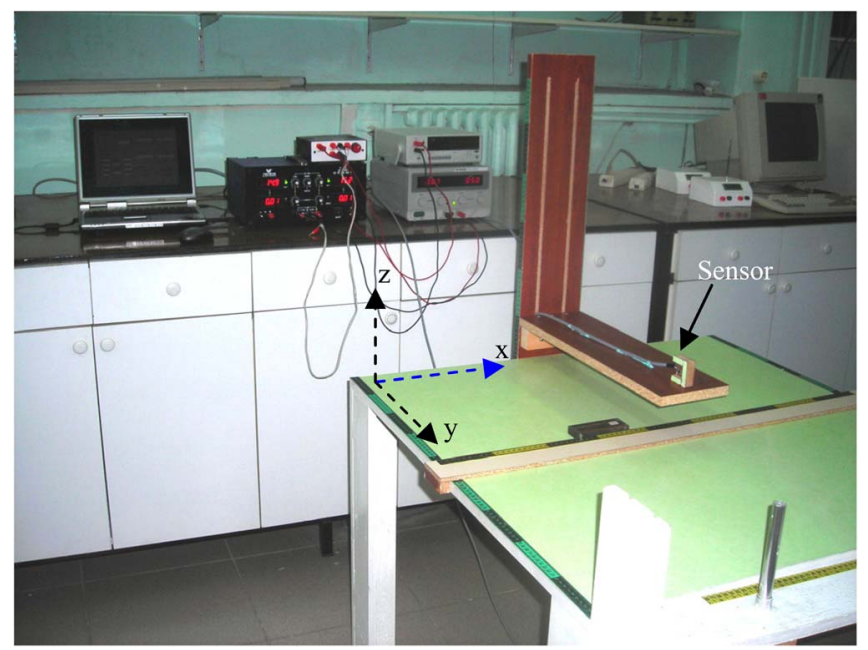

Fig. 1. Measurement system.

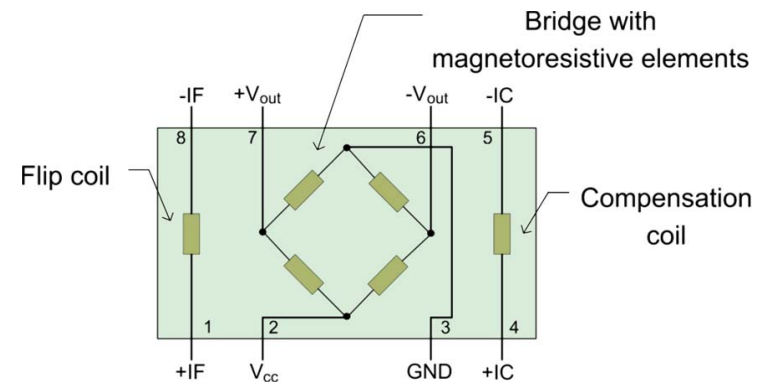

Fig. 2. KMZ51 AMR sensor internal structure.

\section{Measurement System}

The measurement system used in this paper is shown in Fig. 1.

The KMZ51 anisotropic magnetoresistive sensor (AMR) used for measurement purposes is mounted on a platform performing a 3-D motion. The output voltage of the sensor is sent to a parallel port of the computer after converting it to digital form by an analog-to-digital converter (ADC) with 12-b resolution.

\section{A. KMZ51 AMR}

The KMZ51 is an extremely sensitive magnetic field sensor, employing the magnetoresistive effect of thin-film Permalloy. The sensor contains one magnetoresistive Wheatstone bridge and integrated compensation and set/reset conductors. The integrated compensation conductor allows magnetic field measurement with current feedback loops to generate an output that is independent of drift in sensitivity. With the integrated set/reset conductor, the orientation of sensitivity may be set or changed (flipped). A short current pulse on this conductor is needed to recover (set) the sensor after exposure to strong disturbing magnetic fields. A negative current pulse will reset the sensor to reversed sensitivity. By use of periodically alternated flipping pulses and a lock-in amplifier, output will become independent of sensor and amplifier offset, as shown in Fig. 2 [17]. 
TABLE I

Characteristic Parameters of the Sensor

\begin{tabular}{|l|l|c|c|c|c|}
\hline \multicolumn{1}{|c|}{ SYMBOL } & \multicolumn{1}{|c|}{ PARAMETER } & MIN. & TYP. & MAX. & UNIT \\
\hline VCC & Bridge supply voltage & - & 5 & 8 & V \\
\hline S & Sensitivity (uncompensated) & 12 & 16 & $\mathrm{mV} / \mathrm{V}$ \\
\hline Voffset & Offset voltage & -1.5 & - & +1.5 & $\mathrm{mV} / \mathrm{m}$ \\
\hline Rbridge & Bridge resistance & 1 & - & 3 & $\mathrm{~kW}$ \\
\hline Rcomp & Compensation coil resistance & 100 & 170 & 300 & $\mathrm{~W}$ \\
\hline Acomp & Compensation coil field factor; note 1 & 19 & 22 & 25 & $\mathrm{~A} / \mathrm{m} / \mathrm{mA}$ \\
\hline Rflip & Flip coil resistance & 1 & 3 & 5 & $\mathrm{~W}$ \\
\hline Iflip (min) & Minimum recommended flipping current; note 2 & 800 & 1000 & 1200 & $\mathrm{~mA}$ \\
\hline tflip (min) & Minimum flip pulse duration; note 2 & 1 & 3 & 100 & $\mu \mathrm{s}$ \\
\hline
\end{tabular}

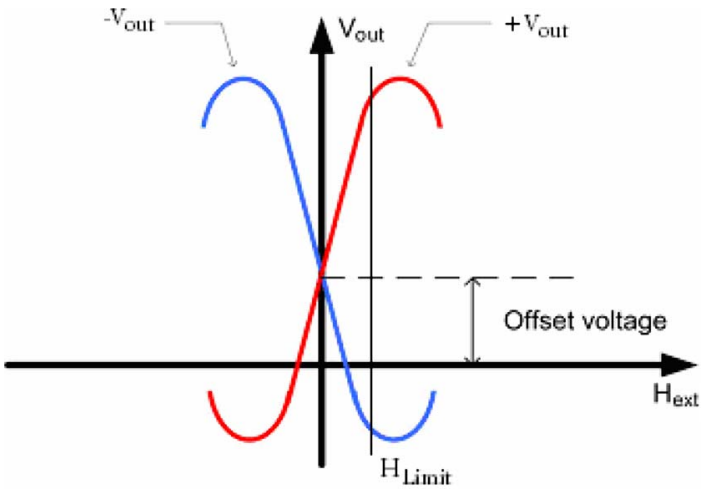

Fig. 3. Typical voltage curve of KMZ51 AMR.

The comparison coil produces a magnetic field which is parallel to the measurement axis; hence, it permits the measurement of the magnetic field ensuring not to exceed the sensitivity of the output by means of the feedback loop. A flip coil leads to changes in the magnetic field that occurred within the sensor for aligning its sensitivity. Furthermore, this coil is also used to measure the offset voltage of the sensor. A switching action between positive and negative output voltages can be produced by applying two directional pulses to the flip coil. The appropriate current value for switching may vary between 800 and $1200 \mathrm{~mA}$. In this paper, a current of $1000 \mathrm{~mA}$ is applied. Hence, it can be ensured that the sensor is aligned to a position to take measurements by changing the orientations of magnetic moments existing on thin films of the sensor. The characteristic parameters of the sensor used are given in Table I.

\section{B. Readings of Sensor Voltage}

The sensor used produces two voltages $-V_{\text {out }}$ and $+V_{\text {out }}$ corresponding to the magnetic field sensed (Fig. 3). Since the value of the Earth magnetic field is not higher than the value of $H_{\text {limit }}$ which is the boundary magnetic field value, the two output voltage variations of the sensor are linear. Therefore, a circuit is designed (Fig. 4) for the purpose of constituting only one output voltage, amplifying the output voltage, and rectifying the output voltage as a dc voltage. As shown in Fig. 4, first, a single voltage is obtained by summing the output voltages $-V_{\text {out }}(-2.5241 \mathrm{~V})$ and $+V_{\text {out }}(+2.5241 \mathrm{~V})$ of the sensor, and then, this voltage is amplified 558 times in stage 2. However, during taking the measurements, it is observed that the sensor also produces an ac voltage of about $50 \mathrm{mV}$ in addition to the dc output. The result of it is that increases and decreases occur at the output voltage. To eliminate the errors arising from these happenings, an ac/dc converter is utilized. By the use of this circuit, the ac part of the signal could be completely eliminated, and a dc output voltage could be obtained.

The analog sensor signal obtained at the output of the ac/dc converter is applied to the input of the 12-b ADC, and the digital form of the signal is applied to the computer through a parallel port (Fig. 5).

The sensor is operated manually, and the digital form of the output signal is stored in the computer synchronously by pressing a button. This assures and increases the accuracy of the measurements.

\section{Control Program of Measurement System}

The flowchart of the data acquisition and measurement is shown in Fig. 6.

When the start button is pushed, the program requests an experiment number, the name of the test material, dimensions of the material, and the name of the file into which the record is stored. If the dimensions of the material are not wanted to be entered, the program skips to the final stage and requests the file name storing the data from the user. Then, the sensor number from which the data are transferred is addressed, and the dimensions of the area to be scanned and step size are entered. At the end, the program is ready to transfer the sensor data to the computer. 


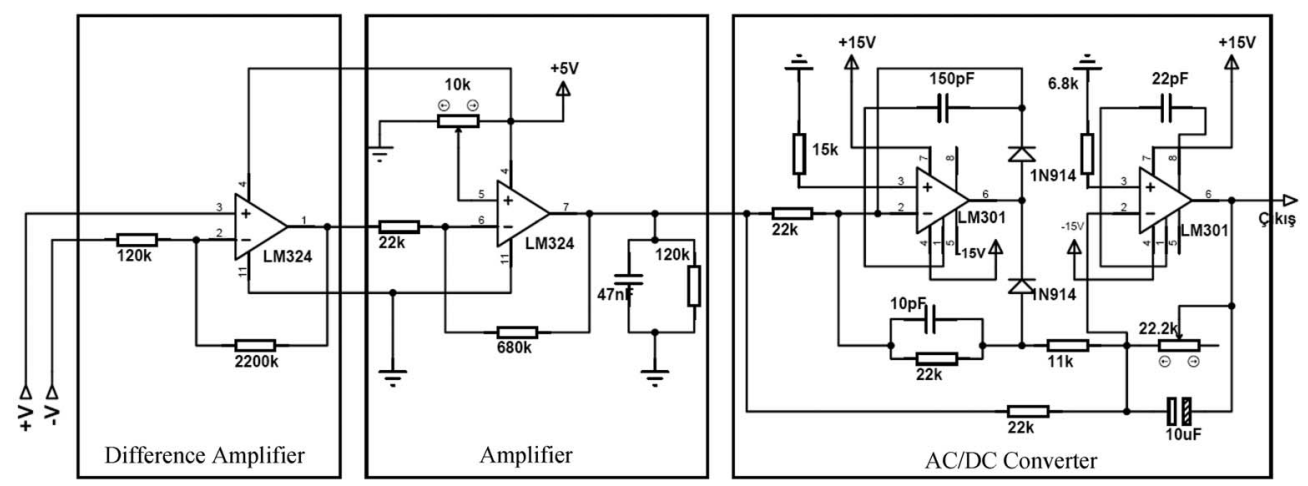

Fig. 4. Amplifier and ac/dc converter.

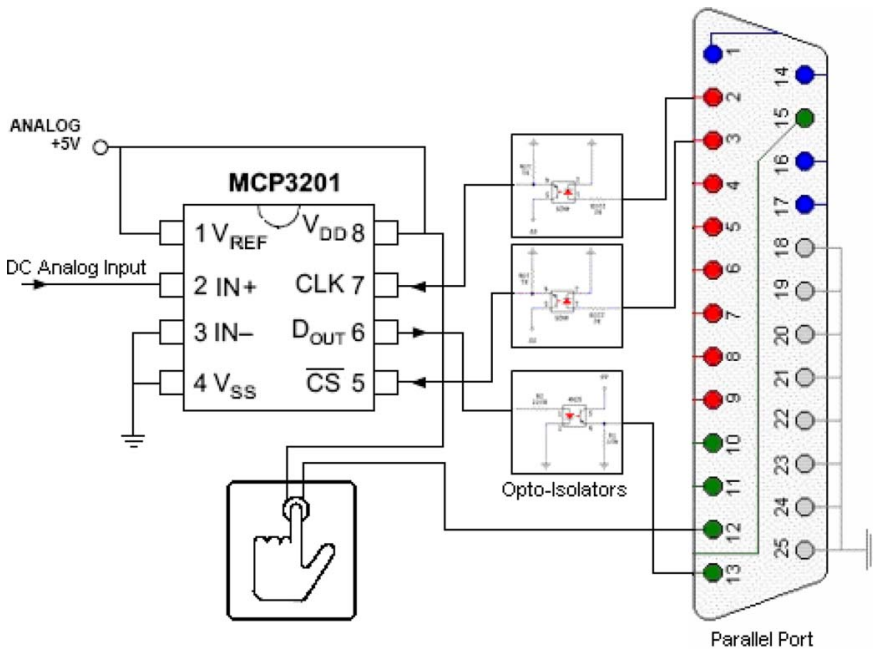

Fig. 5. 12-b ADC circuit.

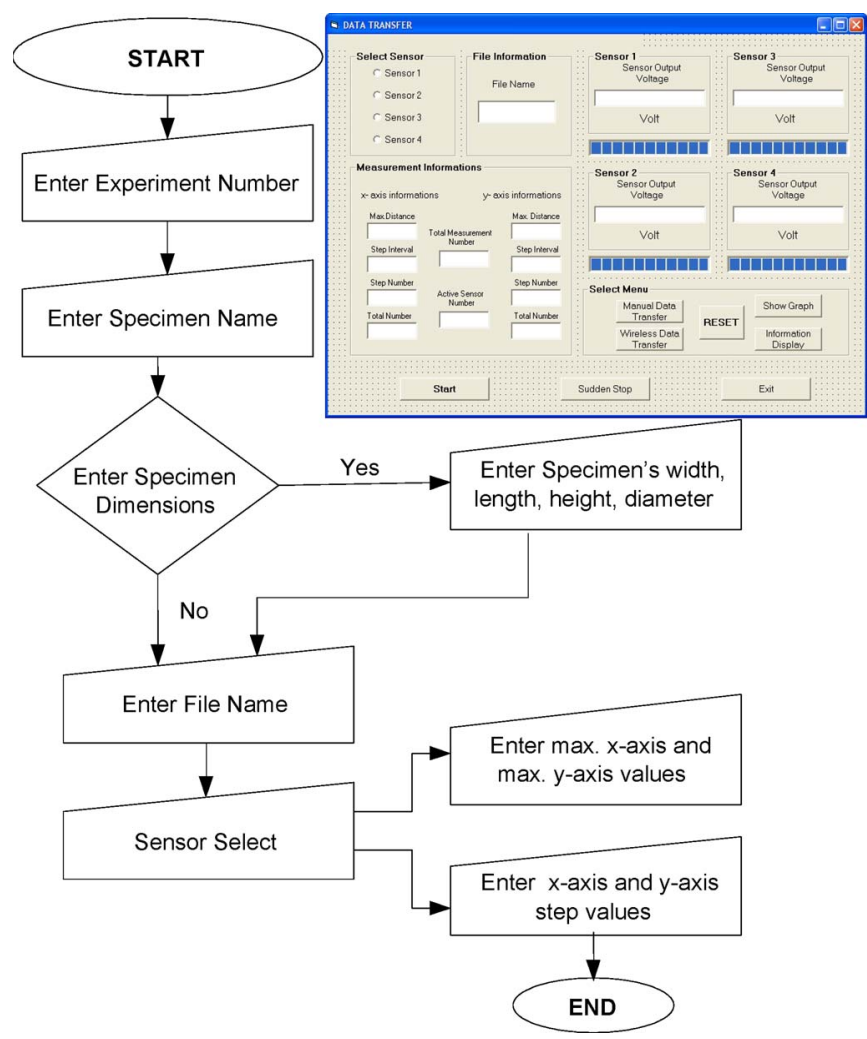

Fig. 6. Flowchart of the data acquisition and measurement.
TABLE II

Chemical Composition of the Materials Used (in Percent)

\begin{tabular}{|c|c|c|c|c|c|c|c|}
\hline SAE/AISI & $\mathrm{C}$ & $\mathrm{Si}$ & $\mathrm{Mn}$ & $\mathrm{P}_{\max }$ & $\mathrm{S}_{\max }$ & $\mathrm{Cr}$ & $\mathrm{Mo}$ \\
\hline 1030 & 0.28 & 0.15 & 0.60 & 0.040 & 0.050 & - & - \\
& 0.34 & 0.35 & 0.90 & & & & \\
\hline 1035 & 0.32 & 0.15 & 0.60 & 0.040 & 0.050 & - & - \\
& 0.38 & 0.35 & 0.90 & & & & \\
\hline 1040 & 0.37 & 0.15 & 0.60 & 0.040 & 0.050 & - & - \\
& 0.44 & 0.35 & 0.90 & & & & \\
\hline 1060 & 0.55 & 0.15 & 0.60 & 0.040 & 0.050 & - & - \\
& 0.65 & 0.35 & 0.90 & & & & \\
\hline 4140 & 0.38 & 0.15 & 0.50 & 0.035 & 0.035 & 0.90 & 0.15 \\
& 0.45 & 0.40 & 0.80 & & & 1.20 & 0.30 \\
\hline 8620 & 0.18 & 0.15 & 0.60 & 0.040 & 0.040 & 0.40 & 0.15 \\
& 0.23 & 0.35 & 0.90 & & & 0.60 & 0.25 \\
\hline
\end{tabular}

In addition, the "Wireless Data Transfer" button can initiate a wireless data transfer. If the user wants to get data manually, the "Manual Data Transfer" button is used. The voltage from the sensor can be seen by pushing the "Show Graph" button. If, for any reason, the data gathering process is stopped, a "Sudden Stop" button is used to continue data gathering from the previous step. With the help of the "Show Information Display" button, the user is able to reach the geometric properties of the material tested, sensor position, and instantaneous data information. The program is ended with pressing the "Exit" button, and it is closed.

\section{Magnetic Materials Tested}

The materials used in the tests and measurements are those widely used in industry for manufacturing such as axle, shaft, transmission shaft, gear, bolt, and mine cover. They are compounds made up of $\mathrm{C}, \mathrm{Si}, \mathrm{S}, \mathrm{Mn}, \mathrm{P}, \mathrm{Cr}$, and Mo having ferromagnetic characteristics. Table II gives the percentage of chemical contents of these materials. The geometrical dimensions and magnetic permeabilities of the materials are given in Table III. 
TABLE III

Geometrical Dimensions and Magnetic Permeability of the Materials Used

\begin{tabular}{|c|c|c|c|c|c|}
\hline \multirow[t]{3}{*}{ SAE/AISI } & \multicolumn{5}{|c|}{ Prismatic Materials } \\
\hline & \multirow[t]{2}{*}{ Length $(\mathrm{cm})$} & \multirow[t]{2}{*}{ Width $(\mathrm{cm})$} & \multirow[t]{2}{*}{ Thickness (cm) } & \multicolumn{2}{|c|}{ Relative Permeability } \\
\hline & & & & $\mu_{\mathrm{x}}$ & $\mu_{\mathrm{z}}$ \\
\hline 1030 & 30 & 3 & 1 & 1560 & 350 \\
\hline \multirow[t]{4}{*}{$1030 \mathrm{~A}$} & 30 & 4 & 1 & 1560 & 350 \\
\hline & \multicolumn{5}{|c|}{ Cylindrical Materials } \\
\hline & \multirow[t]{2}{*}{ Diameter $(\mathrm{cm})$} & \multirow[t]{2}{*}{ Height $(\mathrm{cm})$} & \multicolumn{3}{|c|}{ Relative Permeability } \\
\hline & & & $\mu_{\mathrm{x}}$ & \multicolumn{2}{|c|}{$\mu_{\mathrm{z}}$} \\
\hline 1035 & 13 & 1.3 & 1650 & \multicolumn{2}{|c|}{405} \\
\hline 1040 & 4.2 & 11.9 & 235 & \multicolumn{2}{|c|}{2920} \\
\hline 1060 & 5.5 & 12.1 & 295 & \multicolumn{2}{|c|}{3570} \\
\hline 4140 & 14 & 6.1 & 3220 & \multicolumn{2}{|c|}{220} \\
\hline 8620 & 9 & 1.6 & 1520 & \multicolumn{2}{|c|}{305} \\
\hline
\end{tabular}

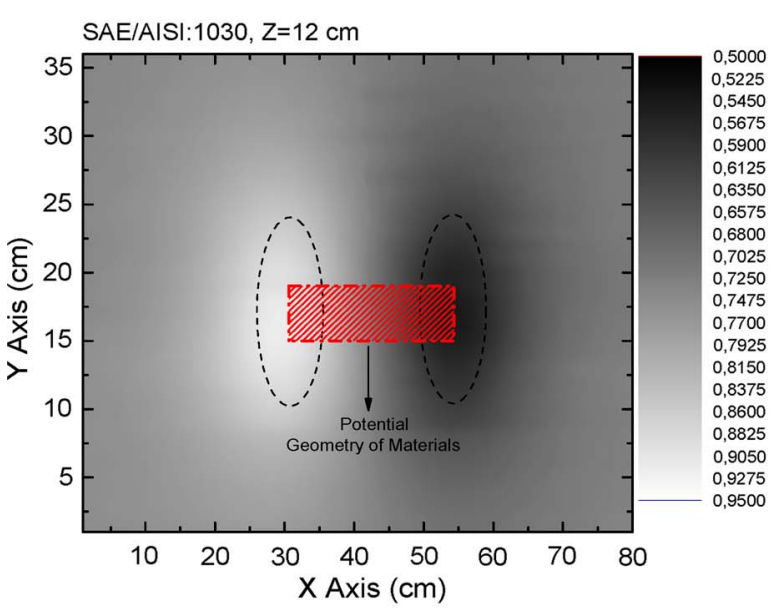

(a)

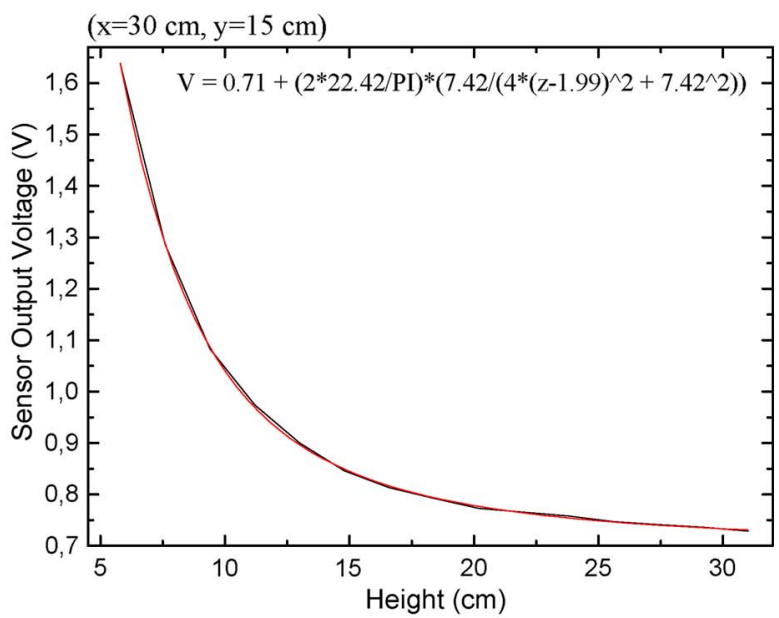

(b)

Fig. 7. (a) Gray scale graphics of the sensor's output voltage distribution for the material AISI:1030. (b) Sensor's output voltage change with the height of the sensor.

\section{Measurement Results and Determination of THE PROPERTIES OF MAGNetic MATERIALS}

In this paper, first, the detection ability of magnetic materials given in Table II from a specified height of the sensor is investigated. The sensor mounted on a scanner is moved over the $x-y$ plane (Fig. 1), and the voltages obtained are arranged as gray scale images [Figs. 7(a), 9(a), 10(a), and 12(a)-14(a)]. Then, the effect of distance between the sensor and the plane under which the magnetic material is located is investigated. For this purpose, the sensor is moved in the direction of $x-z$, and the variation in the sensor output voltage is plotted [Figs. 7(b), 9(b), 10(b), and 12(b)-14(b)]. Looking at the scanned images, the height and surface geometry of the material are tried to be determined.

\section{A. Measurement Results of the Material AISI:1030}

Fig. 7(a) shows the image obtained by scanning the sensor in the $x-y$ plane in $1-\mathrm{cm}$ steps. The height of the sensor is kept at $z=12 \mathrm{~cm}$. The gray levels correspond to the values of the sensor output voltages at that point. Notice that there are two elliptical shapes in the area with different color levels. The reason of it is that the directions of the vertical components of the magnetic flux are opposite to each other for the regions where the magnetic flux lines enter and exit the material. This is verified by the finite-element method (FEM) analysis. This looks like a bar magnet. Therefore, we can conclude that such a distribution can be created by a prismatic bar magnet. Furthermore, it can be noticed that the width of the rectangle drawn for the upper surface geometry of the material can coincide with the distance of focal points of the ellipses. The actual width of this sample is $3 \mathrm{~cm}$. The estimation is reasonable enough.

As shown in Fig. 8, the Earth magnetic flux is oriented toward the material in the region, and it continues at the input side after the material. In this case, the component $B_{z}$ at the input side of the material first increases and then decreases. It shows the same behavior at the output side of the material. Since the sensor output voltage is directly dependent on the component $B_{z}$ of the magnetic flux, the change of sensor output voltage along the material ( $x$-axis) will be as shown in Fig. 15(a). 


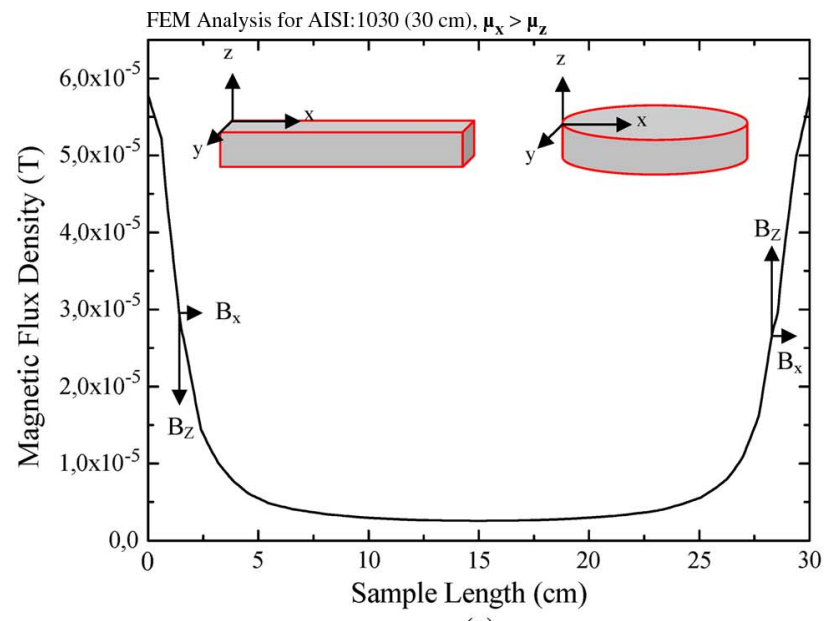

(a)

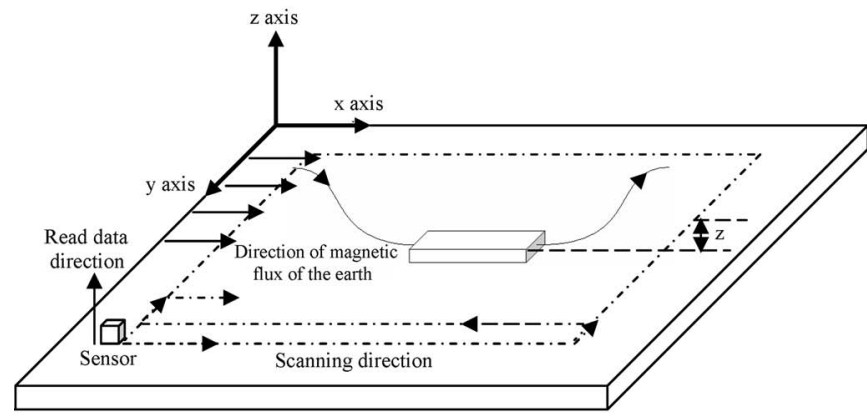

(b)

Fig. 8. (a) Behavior of the Earth magnetic flux in a region where cylindrical materials with a prismatic shape and a height of greater than its diameter are found. (b) Scanning process.

In Fig. 7(b), the effect of distance $z$ between the material and the sensor can be seen. As you notice from this graphics, for $z>30 \mathrm{~cm}$, there will be no change in the sensor output voltage when it is moved over the material. Therefore, it can be said that the American Iron and Steel Institute (AISI):1030 material can be identified for $z<=30 \mathrm{~cm}$. In general, more clear graphics can be obtained for smaller distances.

\section{B. Measurement Results of Material AISI:1035}

Fig. 9(a) shows the output voltage distribution of the sensor that is positioned $z=10 \mathrm{~cm}$ above the $x-y$ plane and moved in $1-\mathrm{cm}$ steps to scan the area. It is noticed that the region of the voltage distribution is in a shape of a circle. This gives directly the upper surface geometry of the material. However, it is not possible to determine the diameter of the circle directly from the image. In this graphics, there are two half circles which intersect each other. One of the half circles is dark, and the other is light in color. As you notice, this image is very different from the image obtained for the material AISI:1030. The reason that the colors are different is the fact that the magnetic flux lines entering and outgoing are opposite in directions. In both of the materials (AISI:1030 and AISI:1035), magnetic flux lines of the Earth are drawn to the magnetic material. They take the original form after the material again (Fig. 8). The reason for this is that the number of dipoles along the diameter ( $x$-axis) is much more than the height $\left(\mu_{x}>\mu_{z}\right)$ since, as shown in Table III, the diameter of this cylindrical material is greater than the height. In this case, the magnetic flux will flow along the diameter ( $x$-axis). This reasoning is verified by the FEM analysis (Fig. 8).

In Fig. 9(b), the effect of vertical distance on the output voltage is shown. When $z$ is $22 \mathrm{~cm}$, the material AISI:1035 cannot be determined by use of this measurement system. In order to get a clear picture, the vertical distance must be close to the surface.

\section{Measurement Results of Material AISI:1040}

Fig. 10(a) shows the output voltage distribution of the sensor that is positioned $z=10 \mathrm{~cm}$ above the $x-y$ plane and moved in 1-cm steps to scan the area. In this image, there is only one light-colored region that is different from previous images. This case can be interpreted as follows: The Earth magnetic flux lines are not drawn to the surface of the material, but they enter in one side and exit at the other side of the material. Therefore, it can be said that the sensor can only sense the flux entering the material. The reason for it is that the carbon percentage may be much more than that of the other materials. Since the carbon is not an element inside a steel, it may be in the form of $\mathrm{Fe}_{3} \mathrm{C}$. This content may give rise to harden the steel. As the carbon content increases in the material, the magnetic characteristic of it also increases in the iron. As seen in Table III, the magnetic permeability of this material is greater than that of the others. Furthermore, as the diameter of this cylindrical material is less than the height of it, the number of dipoles in the height ( $z$-axis) is much more than that of the other direction $\left(\mu_{z}>\mu_{x}\right)$. In this case, the magnetic flux will flow along the height ( $z$-axis). This reasoning is verified by the FEM analysis (Fig. 11).

As shown in Fig. 11, the magnetic field flux normally flowing through the $x$-axis is changing its direction to the $x-y$ plane when it approaches the plane. The sensor gives a voltage proportional to the magnitude of the magnetic flux $B_{z}$. Although the voltage of the sensor is constant outside the $B_{z}$ sample, it changes over the sample during scanning. However, since the magnetic flux going out from the sample is far away from the sensor, no reverse voltage is observed at the sensor voltage as opposed to the prismatic samples (Fig. 16). Furthermore, Fig. 10(b) shows the curve, which is a function of voltage versus distance. As it can be seen, the material AISI:1040 cannot be determined from the distance that is more than $z=22 \mathrm{~cm}$.

\section{Measurement Results of Material AISI:1060}

Fig. 12(a) shows the image taken from a distance of $z=$ $10 \mathrm{~cm}$ from the surface of the material. The area is scanned in the $x-y$ plane with a step length of $1 \mathrm{~cm}$. This resembles the graphics of AISI:1040. As seen in Table II, the high carbon content can give rise to this shape. However, as seen in Table III, the magnetic permeability of this material is also greater than that of the others. Furthermore, the diameter of this cylindrical material is also greater than the height of the material, and the number of dipoles in the height ( $z$-axis) is more than that of the other direction $\left(\mu_{z}>\mu_{x}\right)$. This situation causes the Earth magnetic flux to behave like in Fig. 11. The diameter of the object cannot be determined from this figure as in the case of 


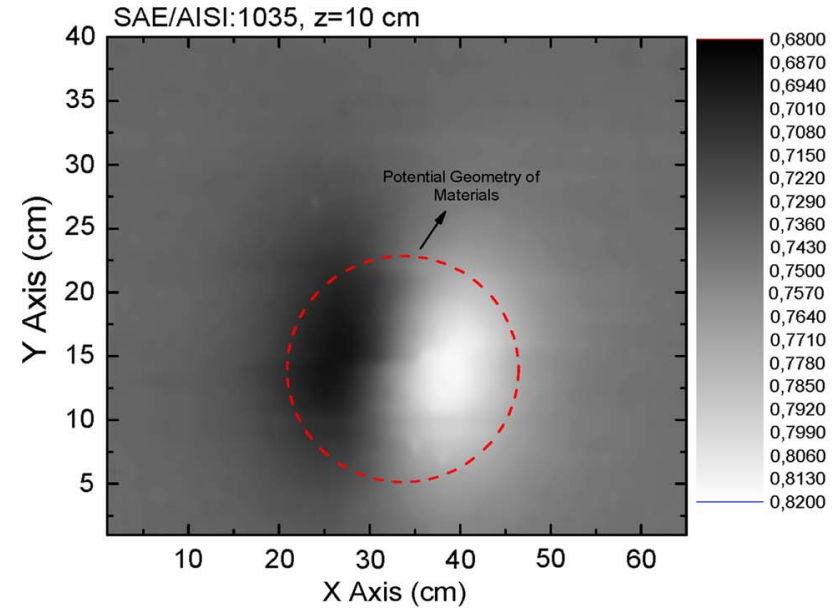

(a)

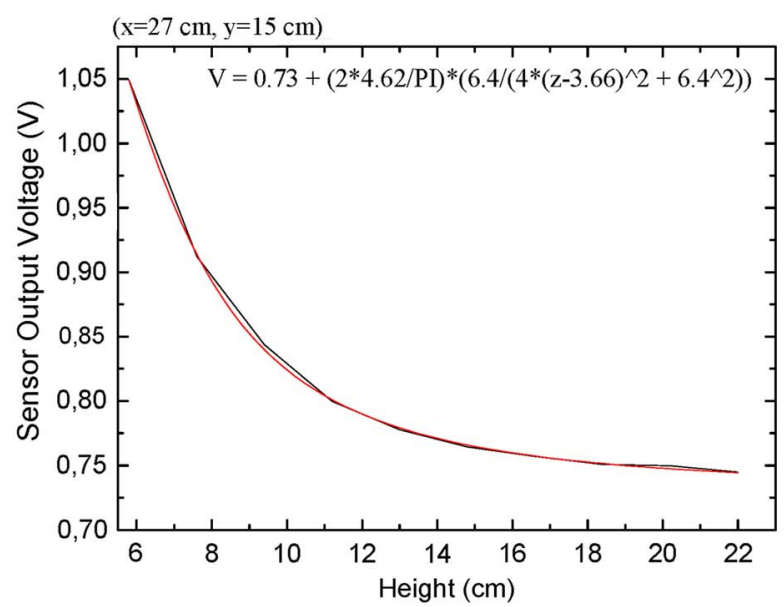

(b)

Fig. 9. (a) Gray scale graphics of the sensor's output voltage distribution for the material AISI:1035. (b) Sensor's output voltage change with the height of the sensor.

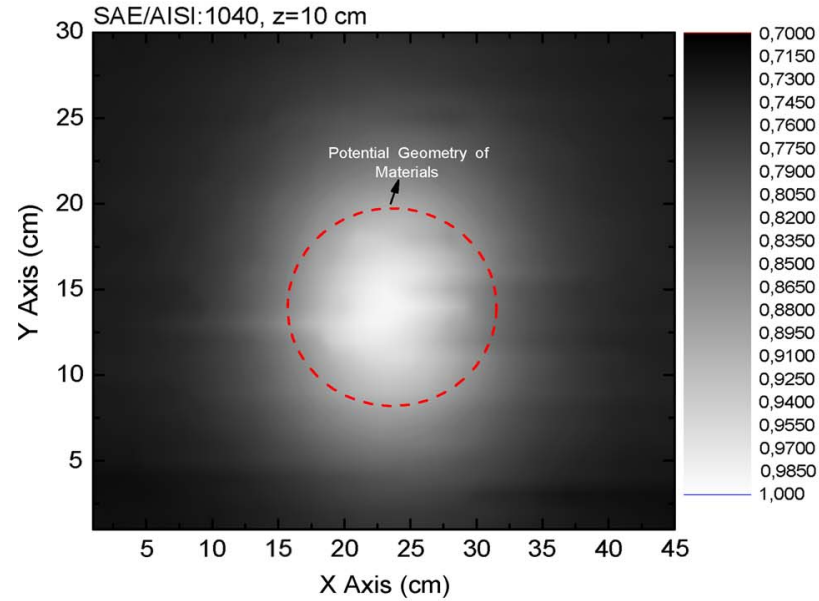

(a)

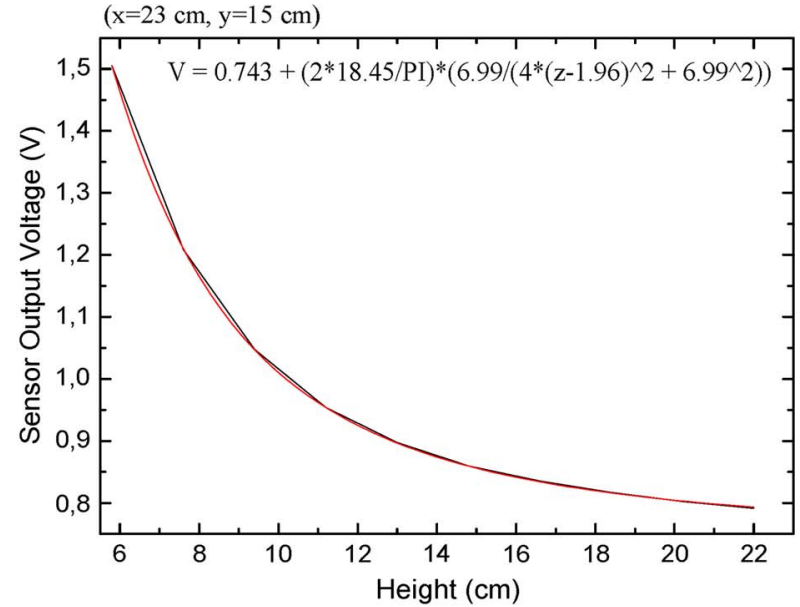

(b)

Fig. 10. (a) Gray scale graphics of the sensor's output voltage distribution for the material AISI:1040. (b) Sensor's output voltage change with the height.

previous graphics. Also, it is not possible to detect the material if the distance is greater that $22 \mathrm{~cm}$ [Fig. 12(b)].

\section{E. Measurement Results of Material AISI:4140}

In Fig. 13(a), the measurements are carried out at a distance of $z=19 \mathrm{~cm}$. Again, the $x-y$ plane is scanned with a step length of $1 \mathrm{~cm}$. It is possible to obtain the appearance of the surface shape of the material from the graphics. It is noticed that there are two distinct regions (the dark and the light) in this image, although the carbon content is the same as that in AISI:1040 (Table II). However, the Si content is higher than that of the previous material. This results in a material that can be magnetized and demagnetized easily. That is, the material is not a permanent magnet. It looses its magnetization easily. Furthermore, the diameter of this cylindrical material is also greater than the height of the material, and the number of dipoles in the diameter ( $x$-axis) is more than that of the other direction $\left(\mu_{x}>\mu_{z}\right)$. For this reason, the magnetic flux of the Earth cannot penetrate the material, but it flows over its surface (Fig. 8). The material cannot be detected from a height of $z>32 \mathrm{~cm}$ [Fig. 13(b)].

\section{F. Measurement Results of Material AISI:8620}

The measurement height of the sensor for AISI:8620 is $z=$ $9 \mathrm{~cm}$. The $x-y$ plane is scanned again with a step length of 1 $\mathrm{cm}$. The resulting image is shown in Fig. 14(a). As you notice, again, two intersecting half circles are available in this image. The Si content of this material is the same as that of the other materials except AISI:4140, but the carbon content is less than that of all the other materials. Lowering the carbon content decreases the magnetic properties of the material. Furthermore, the diameter of this cylindrical material is also greater than the height of the material, and the number of dipoles in the diameter ( $x$-axis) is more than that of the other direction $\left(\mu_{x}>\mu_{z}\right)$. This gives rise to an anomaly in the flux of the Earth magnetic field. The flux passes through the surface of the material. It does not penetrate the material (Fig. 8). The material cannot be determined when the distance is greater than $22 \mathrm{~cm}$ [Fig. 14(b)].

\section{Mathematical Model of Output SIGNAL OF THE SENSOR}

When the changes in the sensor output voltage are determined by moving the sensor through the $x$-axis and taking the 


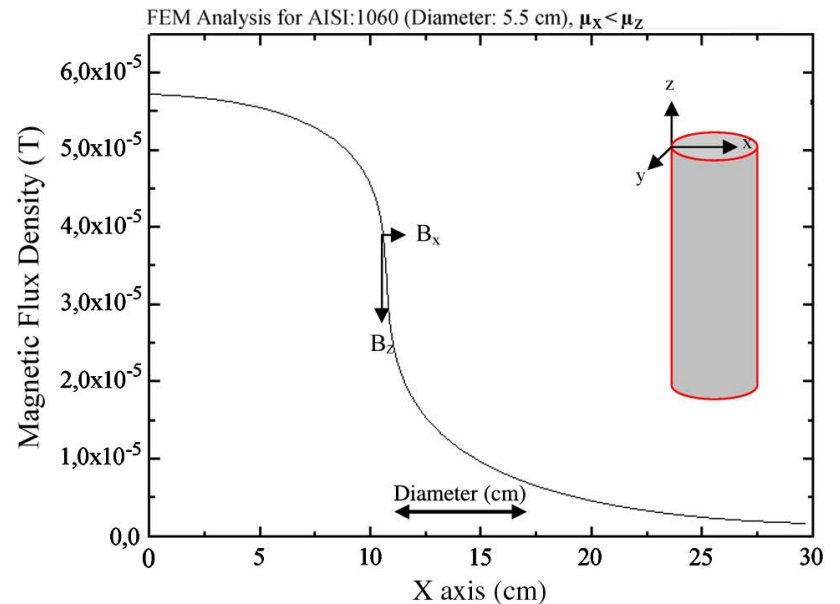

(a)

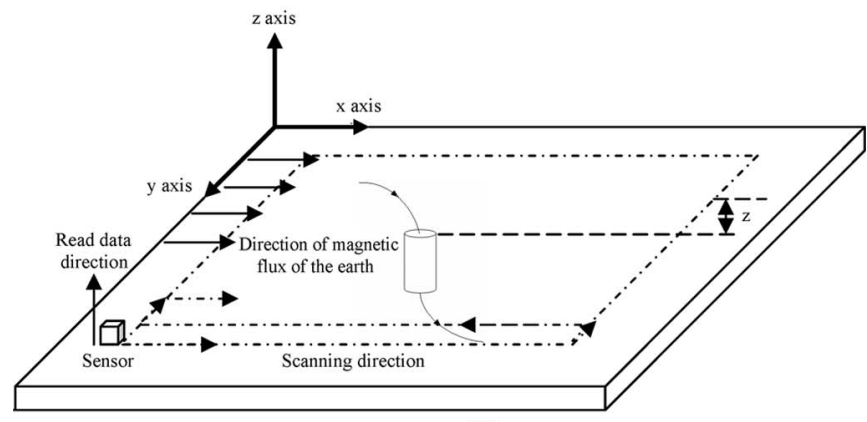

(b)

Fig. 11. (a) Behavior of the Earth magnetic flux in the region where the diameter is less than the height of the material. (b) Scanning process.

distance between the sensor and the material as constant, it is experimentally found that these changes do not have the same characteristics. They have two different characteristics: For the materials AISI:1030, AISI:1035, AISI:4140, and AISI:8620, it is as shown in Fig. 15(a), and for AISI:1040 and AISI:1060, it is as shown in Fig. 16.

We can easily fit a curve, which is the superposition of two Gaussian functions, to the experimentally obtained points in Fig. 15(a). It is shown in Fig. 15(b). The mathematical expression of this curve is given as follows:

$$
\begin{aligned}
V_{\text {output }}=V_{0}+\frac{A_{1}}{W_{1} \times \sqrt{\frac{\pi}{2}}} \times e^{-2\left(\left(x-x_{c 1}\right) / w_{1}\right)^{2}} \\
\quad+\frac{A_{2}}{W_{2} \times \sqrt{\frac{\pi}{2}}} \times e^{-2\left(\left(x-x_{c 2}\right) / w_{2}\right)^{2}} .
\end{aligned}
$$

Although the shape of the sensor output is the same, its parameters $V_{0}, X_{c 1}, W_{1}, A_{1}, X_{c 2}, W_{2}$, and $A_{2}$ can vary where

$V_{0} \quad$ sensor output voltage when the region is empty (no material is available);

$X_{c 1}$ and $X_{c 2}$ peak values of the Gaussian curve;

$W_{1}$ and $W_{2} \quad$ widths of the Gaussian curves;

$A_{1}$ and $A_{2}$ areas between the asymptote $V_{0}$ and the Gaussian curves.

Notice that the experimentally determined variation can be obtained only with a single Gaussian curve, as shown in Fig. 16. The mathematical expression of this curve is given as follows:

$$
V_{\text {output }}=V_{0}+\frac{A}{W \sqrt{\frac{\pi}{2}}} e^{-2 \frac{\left(X-X_{C}\right)^{2}}{W^{2}}}
$$

where $V_{0}$ is the constant value read by the sensor, $X_{c}$ is the coordinate value of the Gaussian curve at its peak, $W_{1}$ is the half width of the Gaussian curve, and $A$ is the area under the Gaussian curve. Here, it is tried to identify the materials by using the variations of some of the variables in both equations based on the physical properties of the material.

\section{IDENTIFICATION OF MATERIAL}

In industrial application, the identification of the length or diameter and the upper surface appearance is enough for material identification. For example, finding the appearance of the upper surface and the length (or diameter) of mines or munitions buried under ground means that they are identified. In this paper, the materials are cylindrical in shape except AISI:1030 which is prismatic. The procedures for the identification of a prismatic material with the use of the measurement system developed here are explained in the following. In addition, it is explained how we can reach the information of the diameter of a material from the result of measurements in the subsequent sections.

\section{A. Determination of the Length of Prismatic Material}

First of all, by moving the sensor along the $x$-axis at a specified height of $z$ when it is just above a material whose geometry is unknown, the values of the sensor output voltage are determined. Next, the graphics similar to Fig. 15 is obtained. The last steps that have to be carried out are shown in Fig. 17.

In Fig. 17, the graphics obtained by moving the sensor along the $x$-axis at a height of $z=9 \mathrm{~cm}$ for the materials (AISI 1030) with the same properties except for the lengths which are 10 and $30 \mathrm{~cm}$, respectively, is shown. In order to determine the length or the diameter of a material, it is necessary to determine the values of the variables of two Gaussian curves providing the variation graphics obtained, as shown in Fig. 15(b). Then, the difference $X_{c 2}-X_{c 1}$ for all materials with different lengths must be determined, as shown in Fig. 17 (see Table IV). The last step is to find the change of the difference $X_{c 2}-X_{c 1}$ according to the length of the material (Fig. 18).

As it can be seen in Fig. 18, the difference $X_{c 2}-X_{c 1}$ obeys the curve whose analytical expression is given as follows:

$$
X_{c 2}-X_{c 1}=(-30.39)+(1.74 \times L)+\left(59.48 \times(0.89)^{L}\right) \text {. }
$$

In this approach, the only thing that has to be done is to determine the difference $X_{c 2}-X_{c 1}$ after obtaining similar graphics for the prismatic materials used in industry. In this paper, similar graphics have been obtained for all the samples tested. Here, only one of them is presented as an example. Furthermore, it is observed that the difference $X_{c 2}-X_{c 1}$ is not dependent on the vertical distance $z$ (Fig. 19).

As it is mentioned previously, in order to get information on the length of the unknown material in the scanning area using our measuring system, all the physical characteristics of the material other than its length have to be known, and its graphics similar to the ones shown in Fig. 18 has to be determined previously. In that case, the value $X_{c 2}-X_{c 1}$ obtained for 


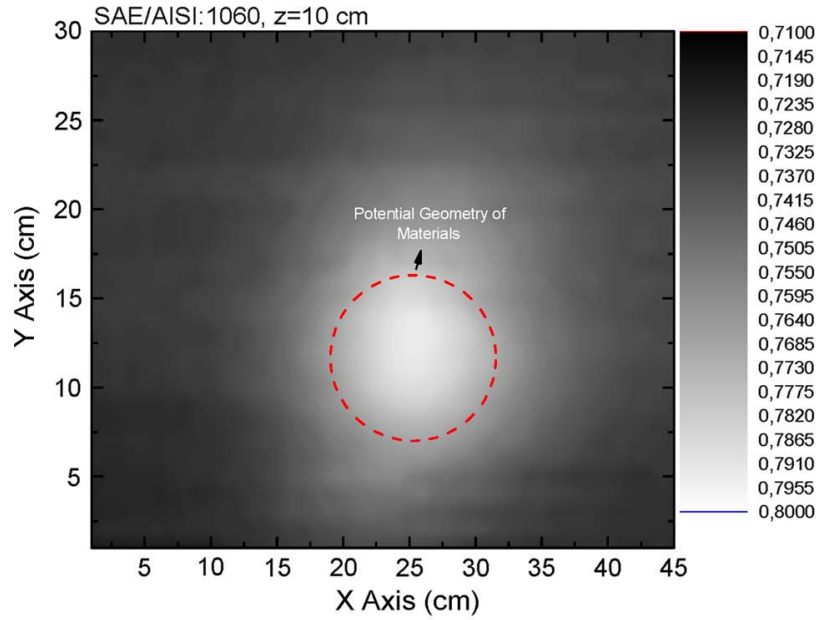

(a)

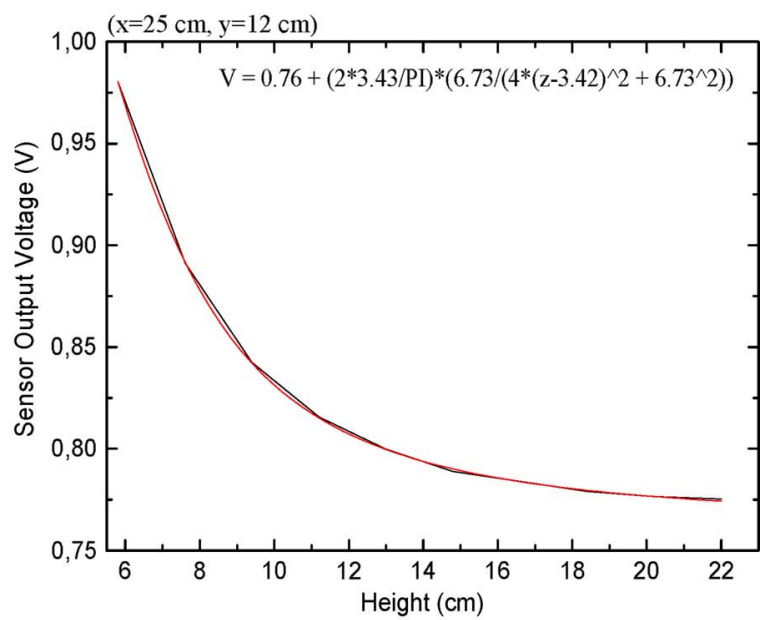

(b)

Fig. 12. (a) Gray scale graphics of the sensor's output voltage distribution for the material AISI:1060. (b) Sensor's output voltage change with the height.

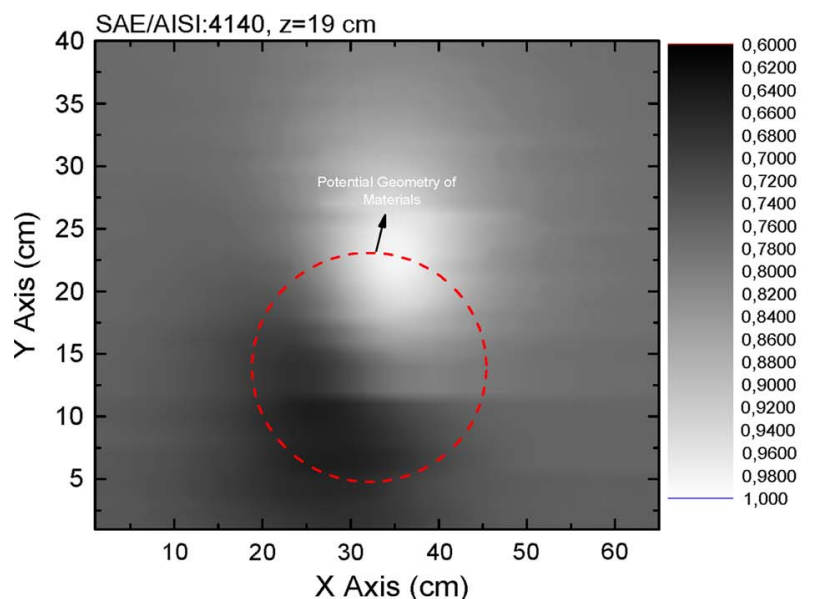

(a)

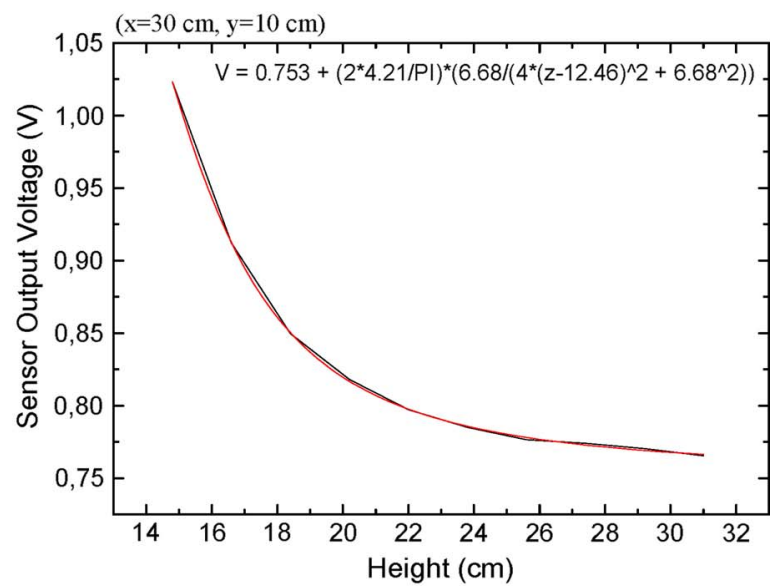

(b)

Fig. 13. (a) Gray scale graphics of the sensor's output voltage distribution for the material AISI:4140. (b) Sensor's output voltage change with the height.

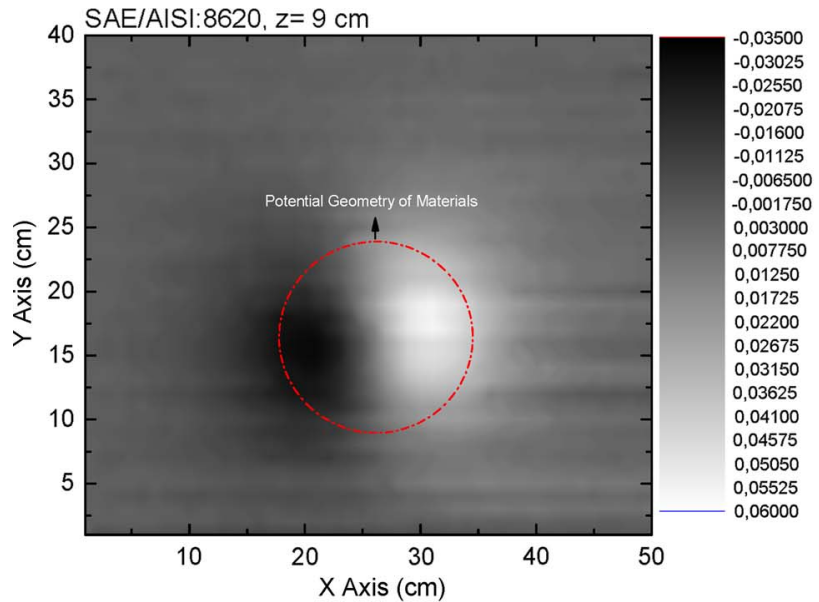

(a)

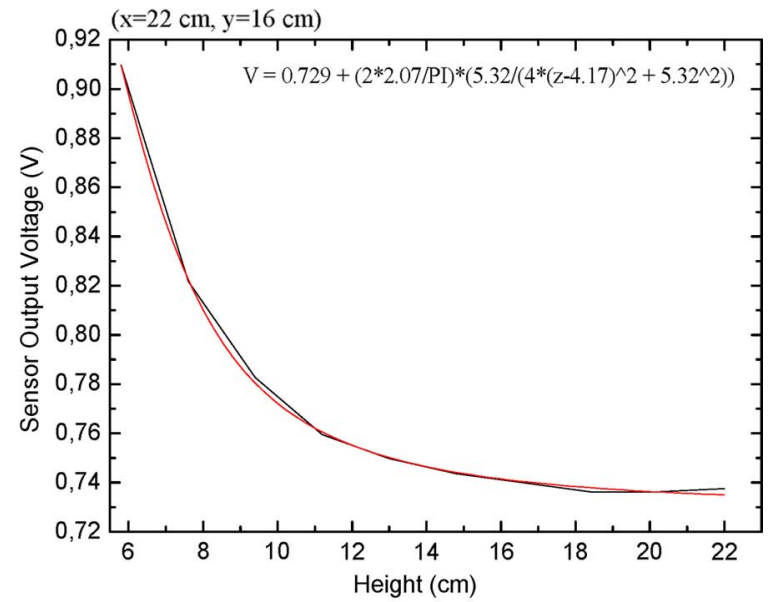

(b)

Fig. 14. (a) Gray scale graphics of the sensor's output voltage distribution for the material AISI:8620. (b) Sensor's output voltage change with the height of the sensor.

the unknown product can give us the length. For example, let us say that we know the Society of Automotive Engineers (SAE)/AISI:1030 material within the scanning region, but we want to know the place and length of the material. In that case, we can utilize the graphics in Fig. 18. After the scanning operation, the value $X_{c 2}-X_{c 1}$ obtained for the material for 


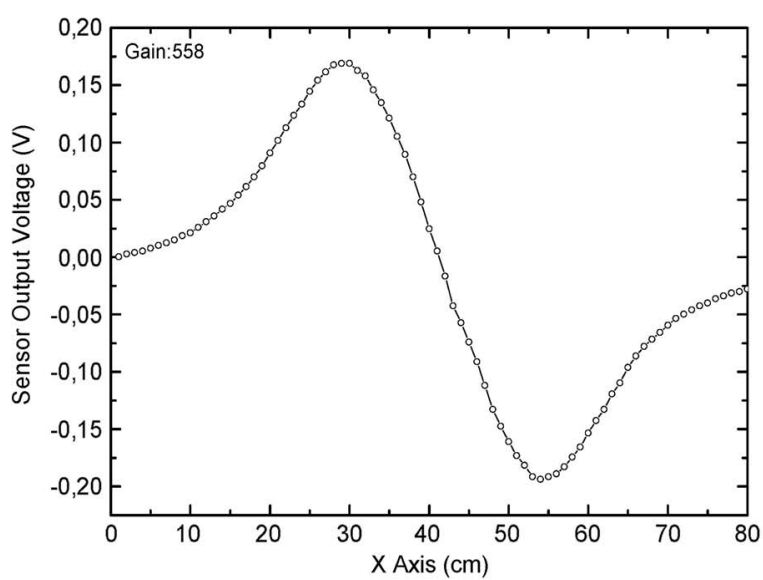

(a)

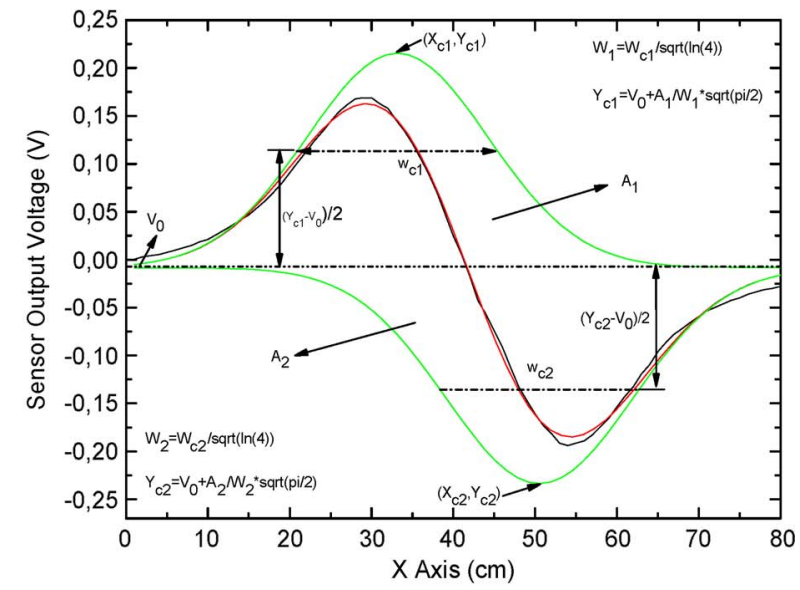

(b)

Fig. 15. (a) Measured output voltage of the sensor at $x$-axis for AISI:1030, AISI:1035, AISI: 4140, and AISI: 8620. (b) Fitted curve.

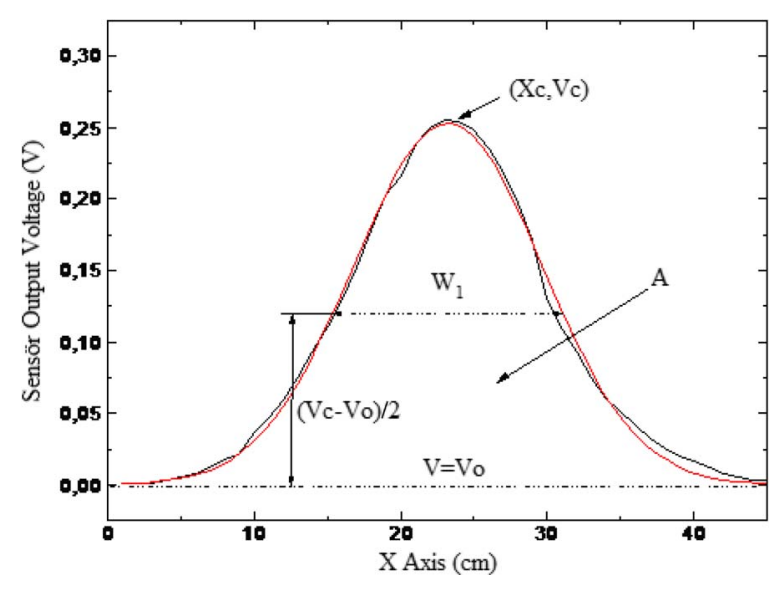

Fig. 16. Measured output voltage of the sensor at $x$-axis for AISI:1040 and AISI:1060 and fitted curve.

which we do not know its length has to be put into Fig. 18 or (3), and the information for the length can be obtained.

\section{B. Identification of Upper Surface of Cylindrical and Prismatic Materials}

In order to be able to identify the geometry of the upper surface of a material by use of the measurement system developed in this paper, the user only has to obtain the graphics shown in Figs. 7(a), 9(a), 10(a), and 12(a)-14(a). However, the user has to determine a height $z$ before scanning operation. The user can move the sensor at an upper direction and find a point where the output voltage of the sensor shows no change. This is the maximum height that a user can use the system. After determining such a height, he/she can scan the region at a height between 0 and $z_{\max }$. However, a lower level is advised since the voltage variations are clearer at lower heights. Table $\mathrm{V}$ gives the maximum vertical distances for the materials to be identified clearly.

In this paper, the experiments were carried out on only cylindrical and prismatic bars. For other types of objects with various geometries, the magnetic images have to be known previously so that someone would be able to assess the graphics appropriately and accordingly.

\section{Determination of the Diameter of Cylindrical Material}

Determination of the diameter of cylindrical materials can be achieved as follows. First of all, the sensor is moved to just above the unknown material at a height of $z$, the area is scanned, and the values of the sensor output voltage are obtained. Next, the variation graphics similar to that in Fig. 10 is obtained. With this information, it can be understood whether the material is cylindrical or not. After understanding that the material is cylindrical, the sensor now is moved only along the $x$-axis at a height of $z$ specified, and the values of the sensor output voltages are measured. Next, the graphics similar to that shown in Fig. 16 is plotted. The experiments carried out by cylindrical materials show that the half width $W_{1}$ of the curve fitted to the sensor output voltages when $z=5 \mathrm{~cm}$ gives directly the approximate value of the diameter.

\section{Determination of the Width of Prismatic Material}

In order to determine the width of a prismatic material, the following process has to be applied. For this purpose, first, the sensor is moved to just above the unknown material at a height of $z$, the area is scanned, and the values of the sensor output voltage are obtained. Next, according the scanning area colored graphics, it is identified that the material is prismatic or cylindrical (Fig. 20). If the material is prismatic (which can be understood from the two separate ellipses in the graphics), the graphics similar to the ones shown in Fig. 20 may be obtained. In this paper, we compared the graphics of two materials AISI:1030 and AISI:1030A which are similar to each other except the widths. We observed that the only difference is that the distances between the focal points of the ellipses are different. We concluded that the distance between the two focal points gives information about the width of the material.

\section{CONCLUSION AND RECOMMENDATION}

In this paper, it is understood that materials with magnetic characteristics can easily be identified by assessing the magnetic anomalies which occurred at the vertical component of the Earth magnetic field. The measurements related to the anomalies have been done by a KMZ51 AMR. First, the appropriate 


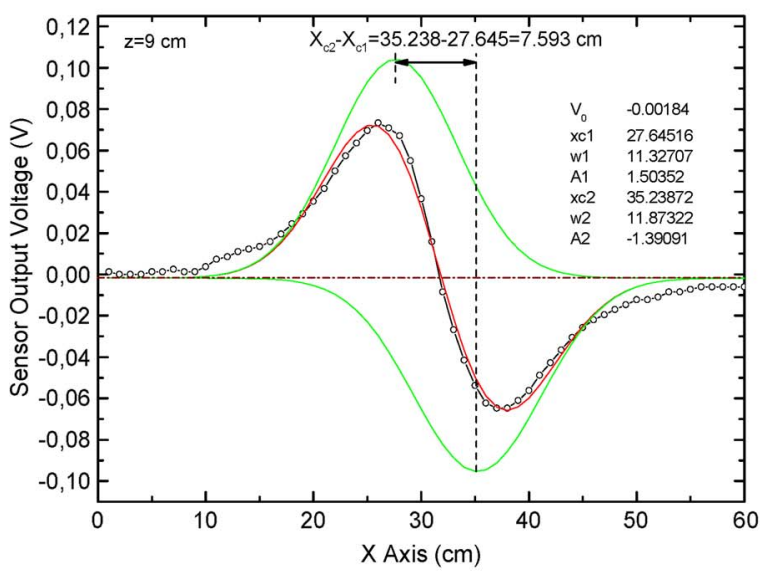

(a)

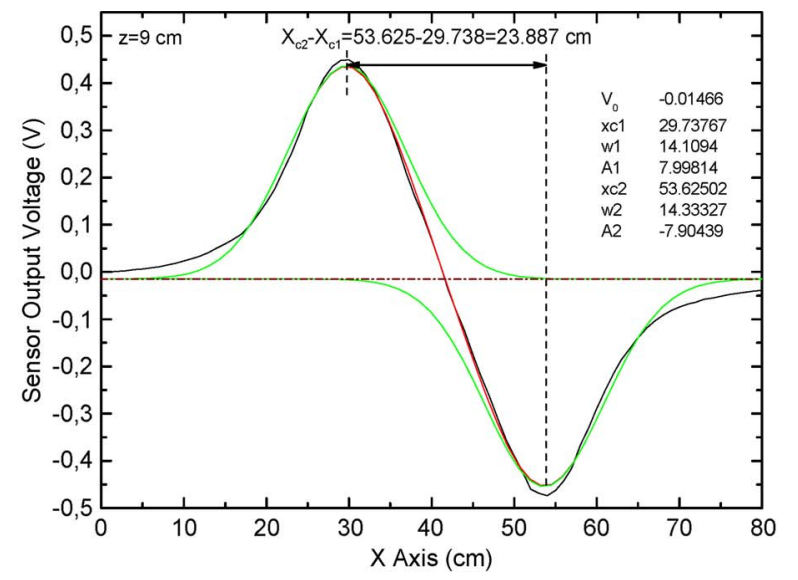

(b)

Fig. 17. Voltage variation at $x$-axis for the material AISI: 1030 at a vertical distance of $z=9 \mathrm{~cm}$. (a) Length is $10 \mathrm{~cm}$. (b) Length is $30 \mathrm{~cm}$.

TABLE IV

VARiation of DifFerence $X_{c 2}-X_{c 1}$ In ACCORDANCE With the LENGTH OF MATERIAL SAE/AISI: 1030

\begin{tabular}{|c|c|c|c|c|c|c|}
\cline { 2 - 7 } \multicolumn{1}{c|}{} & \multicolumn{5}{c|}{ LENGTH } \\
\hline AISI:1030 & $5 \mathrm{~cm}$ & $10 \mathrm{~cm}$ & $15 \mathrm{~cm}$ & $20 \mathrm{~cm}$ & $25 \mathrm{~cm}$ & $30 \mathrm{~cm}$ \\
\hline $\mathrm{X}_{\mathrm{c} 2}-\mathrm{X}_{\mathrm{cl}}$ & 13.085 & 7.593 & 7.912 & 10.292 & 18.691 & 23.887 \\
\hline
\end{tabular}

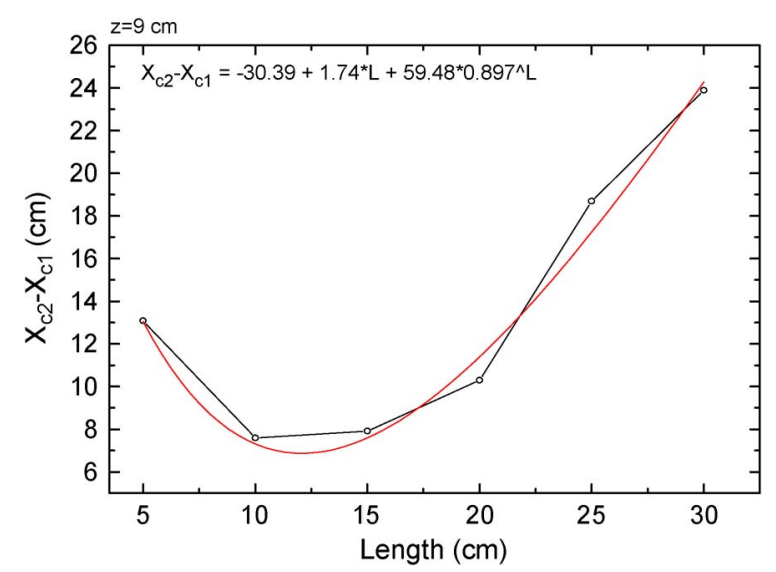

Fig. 18. Variation of difference $X_{c 2}-X_{c 1}$ in accordance with the length of material SAE/AISI:1030.

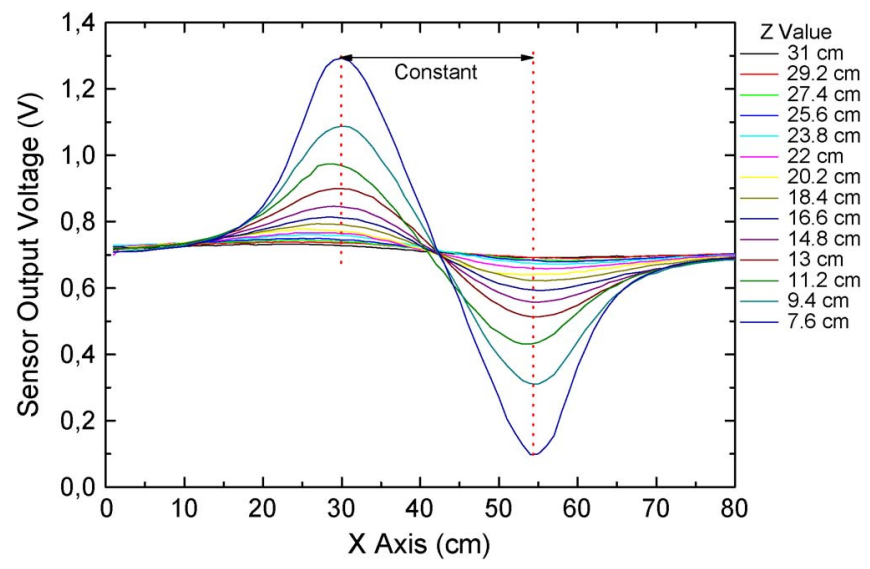

Fig. 19. Sensor output voltage change at the scanning $x$-axis with different heights of the sensor.
TABLE V

VAlues of $z$ In ACCORDANCE With the Type of Material

\begin{tabular}{|c|c|c|c|c|c|c|}
\hline SAE/AISI & 1030 & 1035 & 1040 & 1060 & 4140 & 8620 \\
\hline Vertical distance $\mathrm{z}(\mathrm{cm})$ & 30 & 22 & 22 & 22 & 32 & 22 \\
\hline
\end{tabular}

heights of sensor are determined for magnetic materials having various chemical contents. Then, how the identification of materials with their lengths, diameters, and upper surface images can be achieved is explained by a concrete example.

The types of magnetic materials used in industry can be created by changing the chemical content of the materials based on their application areas. For example, carbon increases the hardness of a steel, but sulfur and phosphorous may make it fragile. Hence, what type of magnetic material which has been used for a product is previously known. Therefore, identification of a magnetic characteristic is not our business. This is not a parameter that we have to determine. However, a necessary condition is that the measurement system has to be calibrated previously for each kind of materials. Also, it is necessary to create a database storing the graphics shown in Fig. 16 for each type of material. Then, the length or diameter of the material can be determined by this measurement system. In this paper, a database holding six types of magnetic materials with various chemical contents is created. The capacity of the database can easily be extended with new kinds of materials by use of the measurement system developed here.

There are some restrictions on this paper. It is clear that the change in the Earth magnetic field in different regions and the availability of some sources of magnetic field other than the Earth magnetic field may affect the sensor output voltage. In such an environment, it is more difficult to determine the dimensions of a material. Furthermore, it must be noted that the method proposed for the determination of dimension depends also on the value of the homogeneous Earth magnetic field. For example, while the strength of the field is $4.4 \times 10^{-5} \mathrm{~T}$ in the region where the measurements took place, it may be different in other locations. Therefore, it is essential to calibrate the measurement system in the region where it has to be used. The magnetic characteristics of the sample and some geometric properties such as the demagnetization factor found near the boundaries of the sample affecting the increase and decrease 


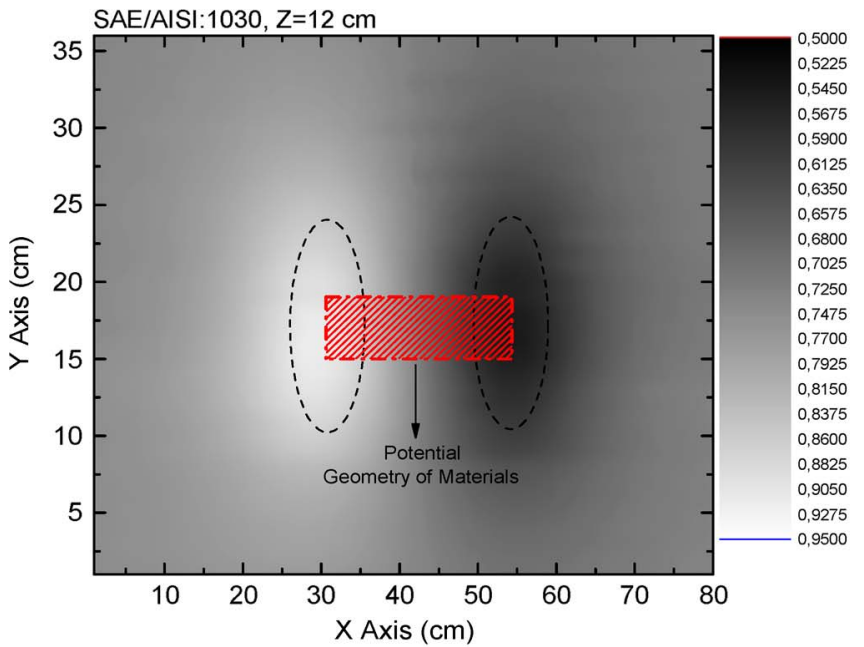

(a)

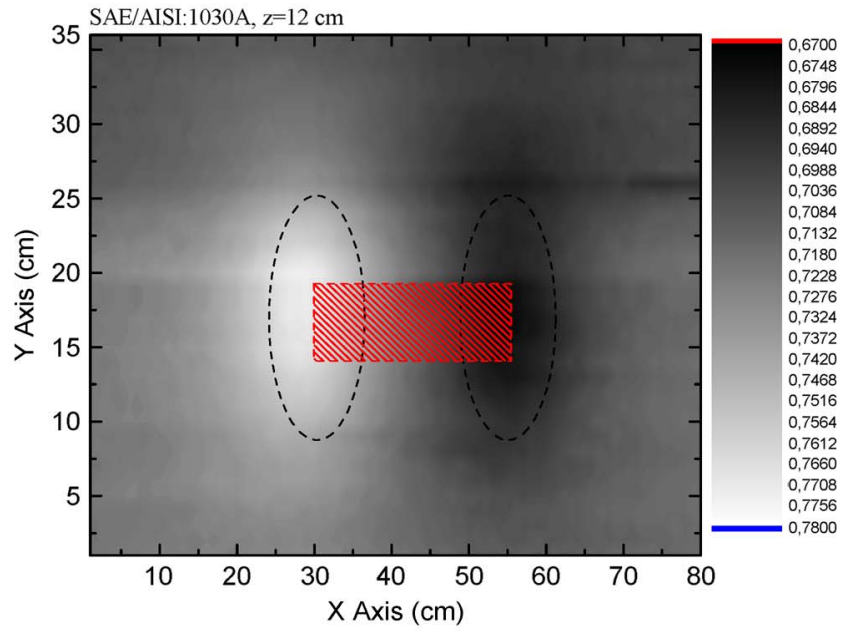

(b)

Fig. 20. Gray scale graphics of the sensor's output voltage distribution for the materials AISI:1030 and AISI:1030A.

of the magnetic field are not the parameters/variables of this measurement system. The system proposed here determines the geometry of a sample whose magnetic characteristics are the same as the characteristics of the known material but having different lengths, widths, and surface shapes from it.

In this paper, the limits of the values for $z$ are listed in Table V. The maximum height where the material can be detected is determined by rising the magnetic sensor step by step. The area scanning was done for each height, graphics were plotted, and the level where no detection could be achieved was determined as the limit value for the height. If we try to identify similar materials in similar environments, then, by considering the limit value that was previously determined, we have to establish an appropriate height for scanning.

The resolution of the ADC is $12 \mathrm{~b}$. If a higher resolution is used for digitization, a more accurate measurement could be achieved. Then, the system could be more robust and sensitive. The boundaries of maximum vertical distances could be extended further. The main advantage of this measurement system is that it utilizes a sensor measuring directly the Earth's magnetic field. It gives the user a more accurate system with less power consumption. This is an innovative system that is used here, and it differs from the similar systems used in industry today.

For future study, we plan to develop an algorithm which will be able to give directly the length or the diameter of a material from the curves (as in Fig. 16 and/or Fig. 18) stored in a data bank for each material. The software to be developed for this purpose will also be able to decide whether the material is cylindrical or prismatic by plotting fitted curves automatically based on the characteristic variations and using (1) and (2) and determining the variables $X_{c 2}-X_{c 1}$ or $W$ on these curves.

\section{ACKNOWLEDGMENT}

The materials and items used for implementing the measurement system are procured by the Olimed Industrial Company Therefore, the authors would like to thank both the university and the company.

\section{REFERENCES}

[1] P. G. Bentley, D. G. Dawson, and D. W. Prine, "An evaluation of acoustic emission for the detection of defects produced during fusion welding of mild and stainless steels," NDT Int., vol. 15, no. 5, pp. 243-249, Oct. 1982.

[2] D. J. Daniels, P. Curtis, and O. Lockwood, "Classification of landmines using GPR,' in Proc. IEEE Radar Conf., Rome, Italy, 2008, vol. 1-4, pp. 2235-2240.

[3] W. R. Scott, "Broadband electromagnetic induction sensor for detecting buried landmines," in Proc. IEEE IGARSS, Barcelona, Spain, 2007, vol. 1-12, pp. 22-25.

[4] J. Deans, J. Gerhard, and L. J. Carter, "Analysis of a thermal imaging method for landmine detection, using infrared heating of the sand surface," Infrared Phys. Technol., vol. 48, no. 3, pp. 202-216, Aug. 2006.

[5] A. Jakobsson, M. Mossberg, M. D. Rowe, and J. A. S. Smith, "Exploiting temperature dependency in the detection of NQR signal," in Proc. ICASSP, 2005, pp. 653-654.

[6] J. A. Bamberger, R. A. Craig, T. Y. Colgan, A. J. Peurrung, B. E. Schmitt, and D. C. Stromswold, "Timed-neutron detection for land mines," in Nuclear Sci. Symp. Conf. Rec., 2003, vol. 2, pp. 1336-1340.

[7] V. Bom, M. A. Ali, and C. W. E. vanEijk, "Land mine detection with neutron back scattering imaging using a neutron generator," IEEE Trans. Nuclear Sci., vol. 53, no. 1, pp. 356-360, Feb. 2006.

[8] A. M. Jacobs, E. T. Dugan, Z. Su, and C. J. Wells, "Detection/ identification of land mines by lateral migration radiography," in Proc. Detect. Abandoned Land Mines, Conf. Publ. IEEE No: 458, 1998, pp. 152-156.

[9] J. E. McFee and Y. Das, "Locating and identifying compact ferrous objects," IEEE Trans. Geosci. Remote Sens., vol. 28, no. 2, pp. 182-193, Mar. 1990.

[10] Y. Ege, O. Kalender, and S. Nazlibilek, "Direction finding of moving ferromagnetic objects inside water by magnetic anomaly," Sens. Actuators A, Phys., vol. 147, no. 1, pp. 52-59, Sep. 2008.

[11] M. H. Kang, B. W. Choi, K. C. Koh, J. H. Lees, and G. T. Park, "Experimental study of a vehicle detector with an AMR sensor," Sens. Actuators A, Phys., vol. 118, no. 2, pp. 278-284, Feb. 2005.

[12] M. Woloszyn, "Detection of ferromagnetic objects in local anomaly of the Baltic Sea," Polish Maritime Res., vol. 15, no. 2, pp. 77-82, Apr. 2008.

[13] E. Galanzha, E. V. Shashkov, T. Kelly, J.-W. Kim, L. Yang, and V. Zharov, "In vivo magnetic enrichment and multiplex photoacoustic detection of circulating tumour cells," Nature Nanotechnol., vol. 4, no. 12, pp. 855860, Nov. 2009.

[14] S. Piro, A. Samir, and L. Versino, "Position and spatial orientation of magnetic bodies from archeological magnetic surveys," Annali Di Geofisica, vol. 41, no. 3, pp. 343-358, Aug. 1998.

[15] T. R. Clem, "Sensor technologies for hunting buried sea mines," in Proc. MTS/IEEE Conf. OCEANS, 2002, vol. 1, pp. 452-460.

[16] T. El Tobelyl and A. Salem, "Position detection of unexploded ordnance from airborne magnetic anomaly data using 3-D self organized feature map," in Proc. 5th IEEE Int. Symp. Signal Process. Inf. Technol., Athens, Greece, 2005, vol. 1/2, pp. 322-327.

[17] KMZ51 Magnetic Field Sensor, Data Sheet, 2000. 


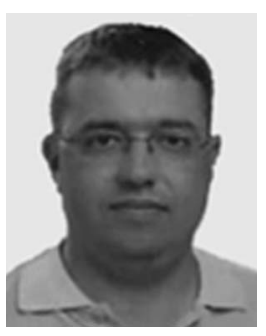

Yavuz Ege was born in Soke, Turkey, in 1973. $\mathrm{He}$ received the M.S. and Ph.D. degrees from the Department of Physics, Institute of Science, Balikesir University, Balikesir, Turkey, in 1998 and 2005 , respectively.

Since 2008, he has been an Assistant Professor with the Department of Physics Education, Necatibey Faculty of Education, Balikesir University. His research interests include solid physics, magnetism, and power electronics.

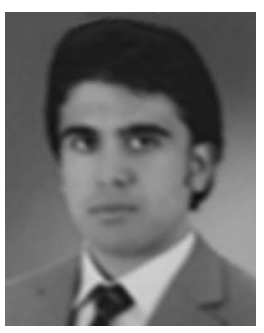

Mehmet Gökhan Şensoy was born in Niğde, Turkey, in 1985. He received the M.S. degree from the Department of Physics, Institute of Science, Balikesir University, Balikesir, Turkey, in 2010.

Since 2010, he has been an Assistant with the Department of Physics, Faculty of Art and Sciences, Rize Üniversity, Rize, Turkey. His research interests include solid physics, magnetism, and digital electronics.

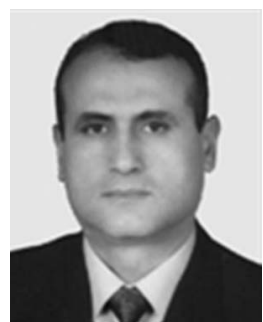

Osman Kalender was born in Buyukbahceli Cankiri, Turkey, in 1964. He received the B.S. degree from the Department of Computer and Electronics Education, Technical Education Faculty, Gazi University, Ankara, Turkey, in 1986 and M.S. degree from the Department of Computer and Electronics Education, Institute of Science, Gazi University Ankara, Turkey, in 1991 and the Ph.D. degree from the Department of Electrical Education, Institute of Science, Gazi University Ankara, Turkey, in 2005.

$\mathrm{He}$ is currently the Chief of Research and Development Department, KZ Mekatronik Company, Ankara. His main research interests include generalized electrical machinery, power electronics, and magnetism.

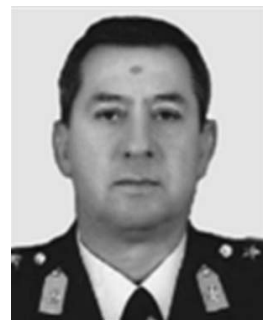

Sedat Nazlibilek received the B.S. and M.S. degrees in electrical engineering from Phosphorous University, Istanbul, Turkey, in 1982 and 1984, respectively, and the Ph.D. degree in electrical engineering from Middle East Technical University, Ankara, Turkey, in 1993.

$\mathrm{He}$ is currently a Research Engineer with the Nanotechnology Research Center, Bilkent University, Ankara. His research interests include control system theory, intelligent control, mobile sensor networks, and robotics. 